\title{
A school-based educational on-site vaccination intervention for adolescents in an urban area in Germany: Feasibility and psychometric properties of instruments in a pilot study
}

\section{Norma Bethke ( $\nabla$ norma.bethke@charite.de)}

Charite - Universitätsmedizin Berlin

\section{Paul Gellert}

Institute of Medical Sociology and Rehabilitation, Charité - Universitätsmedizin Berlin

Nina Knoll

Division of Health Psychology, Department of Education and Psychology, Freie Universitat Berlin Universitatsbibliothek

\section{Niklas Weber}

Medical Directorate, Charité - Universitätsmedizin Berlin

Joachim Seybold

Medical Directorate, Charité - Universitätsmedizin Berlin

\section{Research article}

Keywords: vaccination, on-site, mobile health, prevention, school-based, education, measles

Posted Date: January 16th, 2020

DOI: https://doi.org/10.21203/rs.2.21059/v1

License: (c) (i) This work is licensed under a Creative Commons Attribution 4.0 International License.

Read Full License

Version of Record: A version of this preprint was published at BMC Public Health on January 10th, 2022. See the published version at https://doi.org/10.1186/s12889-021-12443-8. 


\section{Abstract}

Background: Vaccination rates for measles, mumps, and rubella (MMR) and diphtheria, tetanus, pertussis, and polio (Tdap-IPV) are not optimal in German adolescents. Education in combination with easy access vaccination may be a promising approach to improve vaccination rates. In a planned cluster randomized controlled trial (CRCT), we aim at improving MMR and Tdap-IPV rates together with knowledge and self-efficacy in a school setting, the present paper describes the pilot study of this trial.

Methods: Within this pilot study, 863 students from 41 school classes from four schools were included. Optimization and feasibility of the access to schools, recruitment strategies, intervention, and assessment procedures are examined. The course and content of the educational unit was evaluated with a mixed-methods approach. A pre-post measurement design was applied for the vaccination rate in all schools. Additionally, at two schools improvement on vaccination-related knowledge and perceived self-efficacy were measured pre- $(n=287)$ and post- $(n=293)$ educational unit by questionnaire. The remaining two schools provided data only post intervention. Finally, we evaluated the psychometric properties (i.e., reliability, retest reliability, change rates) of the questionnaire, applying Cronbach's alpha, factor analyses, Generalized Estimating Equations and Linear Mixed Models.

Results: Findings of the pilot study indicated good feasibility. Of the total sample, 437 students (50.9\%) brought their vaccination cards to school, 68 students were vaccinated with Tdap-IPV, 11 with MMR. Out of 6 knowledge questions, on average students had $\mathrm{M}=2.84$ ( $\mathrm{Cl}$ 2.69/3.10) correct answers before and $\mathrm{M}=4.45$ ( $\mathrm{Cl} 4.26 / 4.64)$ after class. Ranging from 1 to 4 , self-efficacy scale shown a change of 0.3 points $(p<.001)$ and Cronbach's alpha was .67 and .76 for pre- and post-educational unit respectively and a onefactor solution was found. Content analysis of the five semi-structured group interviews $(n=12,58.3 \%$ female) showed that the length of the intervention was felt by all students to be appropriate. The teaching methods including interactive and social media components were perceived as very good.

Conclusion: A school-based educational and on-site vaccination intervention appears to be feasible in terms of procedures and the adequacy of the instruments for the adolescent target group.

\section{Background}

With the Global Vaccine Action Plan (GVAP) the World Health Organisation (WHO) has set the global goal of increasing vaccination coverage together with eradication and elimination of infectious diseases including measles, polio, or pertussis by 2020 [1]. From 2002 to 2018, the region of the Americas was the only out of six WHO regions that could be considered as consistently measles-free [2]. However, even in this region, more than 10 countries had to report endemic measles transmissions again in both 2018 and 2019 [3]. For Germany, vaccination coverage for basic immunization and catch-up vaccination, for mumps, measles, and rubella (MMR) as well as for tetanus, diphtheria, pertussis, and polio (Tdap-IPV) are too low and have been stagnating for years [4-6]. Measles outbreaks endanger the health of infected and non-vaccinated persons every year; $30 \%$ of infected persons develop complications [7]. In addition to 
individual health risks, measles also represent an immense economic burden for the health system. Even of small measles outbreaks, which have been defined as below 300 cases, the direct and indirect costs exceed the costs of a national vaccination programme many times over with a benefit cost ratio of 2.21 to 4.97 [8]. The cause of large pandemics lies in insufficient immunization rates [9]. Progress towards GVAP global health targets is off track and more efforts on a global level are required, to address systemic weakness and limiting factors.

Effective approaches to increase vaccination rates are needed and school-based on-site interventions may be feasible (for a narrative review of randomized controlled trials testing educational strategies in combination with on-site vaccination, see Appendix 1: samples, intervention components, vaccinations carried out, vaccination process, outcome measures and results). Whereas there is evidence on schoolbased interventions to increase vaccination rates for influenza $[10,11]$ and sexually transmitted infections/human papillomavirus (STI/HPV [12-19]), school-based vaccinations against diseases such as measles, polio, or pertussis have only been addressed rarely within randomized controlled designs [11]. In interventions, common theoretical concepts that were assumed to drive the intervention effects were perceived barriers and benefits (e.g., as part of Protection Motivation Theory (PMT,[20]), Social Cognitive Theory (SCT,[21, 22]), and Health Belief Model (HBM,[23])) as well as perceived risk (e.g., PMT, HBM); both may be altered by knowledge and awareness strategies. Further, a key determinant in most vaccination interventions is self-efficacy - an individual's belief about their competency in goal-directed behaviour (e.g., SCT, PMT). Moreover, environmental barriers and opportunities such as the easiness of access to vaccination and the direct offer for vaccination may increase the likelihood of action (e.g., HBM, SCT). This concept is captured as "cue to action" in the HBM. This is also indirectly included in the SCT as environmental factors. However, cues to action are assumed to work in orchestration with selfefficacy beliefs, knowledge and outcome expectancies [23, 24].

Interventions, which combine educational components with on-site vaccination, appear to be a promising strategy for enhancing vaccination among adolescents (see Appendix 1). These trials have been shown to be feasible and well-accepted by students as well as by school staff. On-site vaccination interventions also include the opportunity to assess vaccination rates and change rates objectively. Regarding on-site vaccination interventions, participation rates of eligible schools ranged widely across studies from 15.0$75.0 \%[10,13,25-27]$, participation rates for eligible students were mostly not reported but ranged for two studies between $34.6 \%$ [18] and $90.3 \%$ [13]. Parental consent rate for vaccination was reported only in three studies and ranged from low $17.0 \%$ [11] to middle $42.5 \%$ [27] to high $76.5 \%$ [26]. Further, in most studies the vaccination coverage of students prior to study participation/intervention was not reported. Vaccination coverage after intervention ranged from around 30\% [10] to 59.0\% [13] to proportions $\geq$ $80.0 \%[11,18,25,27]$. Change rates, meaning the increase in vaccination coverage from pre to post intervention, were reported only in three studies. These were relatively low for two studies, around a $15.0 \%$ increase $[10,26]$ and higher for one study with an increase of 33.9\% [18]. The comparability of on-site vaccination studies is limited because absolute numbers are not always reported e.g. for students who participated in the study vs. students who additionally brought or were in need of a signed consent from their parents for on-site vaccination. Different countries have different legal conditions for vaccination in 
the absence of parents in schools and reports with absolute numbers of all relevant variables are considered indispensable.

Although there is growing evidence on the feasibility and effectiveness of school-based on-site vaccination interventions, more rigorous research is needed, combining theory-driven education, on-site opportunity for vaccination with objective assessment of effectiveness.

\section{Aims}

To identify effective educational strategies to increase vaccination rates for routine vaccines like MMR or Tdap-IPV in students, we developed an evidence based, school-based educational on-site vaccination intervention. [28]. For the on-site vaccination offer, the prevention bus converted into a doctor's office was placed in schools. Information provision and education took place in the classrooms. The aim of the present pilot study was to test access to schools and recruitment strategies for a planned cluster randomized controlled trial. Furthermore, procedures of the educational/basic information intervention in combination with on-site, school-based vaccination were tested regarding feasibility. Measurement instruments including a self-report questionnaire on vaccination-related knowledge and a short version of a vaccination-related self-efficacy scale were to be evaluated concerning internal consistency and sensitivity to change.

\section{Methods}

\section{Design and study overview}

The pilot study was conducted with a cross-sectional design from August to September 2017. All four participating schools were approached with the Prevention Bus for an entire school week (see Fig. 1). The Prevention Bus team on-site at each school consisted of a bus driver and a medical team, including two physicians and two nurses. The bus, which has been converted into a doctor's office in 2016, enables vaccinations to be carried out directly on the school ground to the full extent of medical quality standards (for more information about the Prevention Bus see [28]). Information material and consent documents were distributed to all students and their parents by the school staff one week in advance. During the week on-site, students were addressed in their respective class contexts with two different on-site procedures diverging in degree of information and interactivity (intervention conditions: Educational Class vs. Low Intensity Information Condition). Both procedures ended with a joint visit of the class of the Prevention Bus and the opportunity to be vaccinated with MMR or Tdap-IPV. However, vaccinations could also be carried out on any other day of the week while bus and medical team were on-site.

\section{Participant recruitment and informed consent}


Schools in the pilot study were eligible for participation when they fulfilled two out of three inclusion criteria of the schools eligible for the main trial. Inclusion criteria were being an upper secondary school i.e. a high school, or a vocational school (for more information see Appendix 2 (a)), with at least 200 students in grades 9 to 11, and located in the city center of Berlin. This approach was chosen in order to achieve maximum comparability without interfering with schools eligible for the main trial. School administrations from selected schools were contacted in advance by letter and email and asked whether they wanted to participate. When an initial interest had been expressed, further questions were clarified by telephone or within a personal appointment at the respective school. In the pilot study, schools were not randomized to conditions.

If the school administration had agreed to participate, parents and students were informed one week in advance about the Prevention Bus project. Students within the selected schools were eligible for participation for the educational/basic information components of the intervention if they were currently attending grades 9 to 11. For on-site vaccination, if the vaccination card together with a consent form for the vaccination was completed. All minors had to present a consent form signed by their parents. For this purpose, the school staff provided the students with take home materials consisting of an information letter on the Prevention Bus project and consent forms for vaccination (hard copies). The parents were asked to complete and hand the documents back to their children to bring cards along to school on the day of the intervention. On the day of the on-site intervention all vaccine recipients, including minors, were educated and asked to sign a consent form for vaccination by themselves. In case of missing vaccination documents on the day of the intervention, these could be presented during the course of the on-site week and necessary vaccinations could be carried out at any time in the bus on the following days.

\section{Intervention Conditions}

At all four schools included in the study the Prevention Bus was present for an entire school week (see Fig. 1), which comprises five days. One intervention week comprised only three days due to public holidays (see Table 1). As described above, all students and parents were informed about the Prevention Bus project one week before the bus was at the respective school. The school secretary's office received take-home materials together with a declaration of consent form for the parents. The school administration was instructed to distribute the materials and to remind the school classes 1-2 days in advance to bring the materials, including their vaccination card, along on the day of the intervention.

At each school all potentially participating school classes were allocated lessons over the course of the week in which the students participated in the on-site intervention conditions, differing in information and educational content. While the possibility of being vaccinated was identical for all students at the participating schools, two planned intervention conditions for the main trial were tested, i.e., Educational Class or Low Intensity Information. 


\section{Educational Class Condition}

At three schools (school 1, 2 and 3, see Fig. 1) a 90-minute procedure was carried out in individual school classes (Educational Class Condition [ECC]). This included an educational unit taught by a physician in the classrooms, the checking of vaccination cards, and the completion of the questionnaire by each student. The educational unit consisted of a digital PowerPoint presentation with interactive elements. Topics addressed were the immune system and infectious diseases, vaccination processes, herd protection, as well as risks and benefits specific to the measles vaccination. A group discussion as well as media elements such as newspaper articles and videos were also included. The educational unit was based on three theories of health behavior change, the SCT [21, 22], the PMT [20], and the HBM [23]. It was intended to increase knowledge by providing and discussing information [20-23], to address vaccination/disease-related risk perception by risk communication [20], and to use a testimonial by a fictional role model addressing self-efficacy [21,22]. A detailed description of the educational unit and underlying theories can be found in the study protocol [28]. Immediately after the educational unit and the completion of the questionnaires, a guided tour through the Prevention Bus followed. During this tour, students had the opportunity to directly receive a vaccination if needed. Students could also have the vaccination carried out later in the week.

The ECC procedure largely corresponds to the planned procedure in the main trial. However, in schools 1 and 3 questionnaires were completed by students not only after but also before the educational unit (see Fig. 1) to test sensitivity to change of the items.

\section{Low Intensity Information Condition}

In school 4 (see Fig. 1), a 45-minute unit was conducted with the individual school classes (Low Intensity Information Condition [LIIC]). In each participating class physicians orally provided brief information about the Prevention Bus and vaccinations offered. Detailed vaccination questions were not discussed within the LIIC. Solely organizational information and information already given in the written vaccination consent form were raised. Subsequently, vaccination cards were checked, and the questionnaire was completed. Afterwards, the tour of the bus and the opportunity to receive vaccination directly at the tour or later on, if needed, were identical to the ECC-procedure.

\section{Measures}

To assess feasibility of the recruitment process, of on-site procedures and in order to evaluate measurement instruments, we collected data from seven process indicators and measures. The variables collected were: school recruitment log, vaccination documents, vaccinations delivered, rating of the educational unit, semi-structured interviews on the educational unit, a vaccination-related knowledge scale, and a vaccination-related perceived self-efficacy scale. In addition, covariates were assessed which could influence the vaccination behavior. This mixed-method data assessment facilitated a multitude of 
information feedback and potential target group-specific adaptation of processes and measurement instruments that were tested in the pilot study.

With the school recruitment log recruitment approaches and strategies were documented.

We assessed presence and contents of vaccination documents as an indicator of the feasibility of on-site procedures regarding requirement for vaccination in schools. The number of vaccination cards that were brought to school as well as the number of signed parental consent forms for vaccination were recorded. This allowed us to document who could potentially participate in a vaccination, as all required documents were brought along. In addition, we recorded the vaccination status (vaccinations: type and number of doses received) in order to determine the proportion of students with a need for vaccination. Vaccination status for all standard vaccinations recommended of the German Vaccination Committee "Ständige Impfkommission am Robert-Koch Institut" (STIKO) was documented [29]. All indicators were documented by a physician or nurse, during the ECC/LIIC before vaccination on-site was offered.

For the vaccinations delivered on-site the medical team documented how many students received a vaccination in the Prevention Bus. In this study, combination vaccination against mumps, measles, rubella (MMR [30]) and tetanus, diphtheria, pertussis and polio (Tdap-IPV [31]) were offered. Whether students had an indication/need for vaccination or not was determined again in accordance with the recommendations of the STIKO [29].

The rating of the educational unit by all students in the ECC was documented. The students evaluated the course and content of the educational unit with a single item on a 3-point Likert scale (scale: very interesting, interesting, boring), applied after the ECC took place. Further feedback was recorded with semi-structured interviews on the educational unit with selected students (single and group settings) in the ECC to ascertain how easily understandable the contents of the educational unit were and which components were of particularly high or low interest. In addition, students were asked to evaluate the interactive components of the educational unit. This reflects for example a guided group discussion, which was triggered by a fictional social media post. Students had to evaluate how realistic the scenario in the post was to them. Furthermore, students were asked whether their attitude towards vaccination had changed after the presentation. The interviews were conducted after completing the individual questionnaire, but before students entered the bus.

The vaccination-related knowledge scale indicated, with a maximum of 7 items, the level of immunization knowledge (see Appendix 2 (b)). Figure 2 provides an overview of which items were assessed at which school. Items covered facts about target groups of infectious diseases, prevention of the spreading of infectious diseases, herd immunity, vaccination and side effects of infections. Items were multiple choice, with one correct answer. Across all items an overall knowledge sum score could be generated.

Two different sum scores were calculated in the pilot study. The 4-item sum score included items 1-4 (Childhood Disease, Herd Immunity, Immunization, Measles Outbreak) and was assessed in all four schools (see Fig. 2). In addition, for school 3 and 4 a 6 -item sum score could be computed as all final 
items were applied including the newly successively introduced items 6 and 7 (Infertility, Pregnancy Malformation). A low sum score (0) represents a low level of vaccination-related knowledge and a high score (4 or 6) a high level of vaccination-related knowledge. Item 5 (Bacteria) was not selected for the formation of scales ${ }^{2}$.

The vaccination-related perceived self-efficacy scale, reflected students' beliefs about their own competency to understand, appraise, and apply vaccination-related health information (see Appendix 2 (b)). The scale consisted of a short-version of the health literacy questionnaire HLS-EU Q47 [32]. The short-version was created by selecting those items, which covered vaccination and information on prevention. Students were asked to rate five items on 4-point Likert type scales ranging between 1 (very difficult) and 4 (very easy). A mean score was computed, with low scores representing low and high scores high levels of perceived self-efficacy.

Additionally, covariates, including gender, socioeconomic, and migration status, were assessed on school and/or individual level. Regarding socioeconomic status (SES) two items were applied, assessing whether students had a room of their own $[33,34]$ and had access to reduced fares in public transport and leisure activities (i.e., "berlinpass"). Migration background was documented on school level, indicating the ratio of students with a foreign language background.

\section{Analysis}

Data were analyzed using IBM SPSS Statistics 25. Descriptive data of the school recruitment log was used to evaluate the feasibility of recruitment processes. Prior to scale analyses, missing values for all final vaccination-related knowledge items (ranging from 2.2\% - 7.3\%) and all perceived self-efficacy items (ranging from $9.5 \%-12.0 \%$ ) were imputed with a Multiple Imputation (MI) procedure using fully conditional specification and 20 imputed datasets.

According to the school recruitment log, a ratio between targeted schools and successfully recruited schools was used. Further, absolute numbers of vaccination documents brought to school (the number of vaccination cards present, consent forms returned) and vaccinations delivered on-site were reported. A relative ratio of students with a need for vaccination and vaccinations carried out in this study were reported at a descriptive level.

For the vaccination-related perceived self-efficacy scale, the internal consistency (i.e. Cronbach's Alpha) and the factorial structure (varimax-rotated exploratory factorial analysis [EFA]) was calculated. To determine significant changes from pre to post intervention in vaccination-related knowledge and perceived self-efficacy, Linear Mixed Models (LMM) for continuous outcomes (covariance type = variance components, estimation = Restricted Maximum Likelihood) and Generalized Estimating Equations (GEE) for dichotomous outcomes (distribution = binomial, link function = logit) were used; these allow for an 
adjustment for the nested structure of students in classes and control for the influence of age, gender, and SES. The longitudinal pre-post-educational unit measurements of the questionnaire in the same school class (see Fig. 1, school 1 and 3) were used specifically for the pilot study to test the sensitivity to change of the vaccination-related knowledge and perceived self-efficacy measurements. In addition, we compared schools in which the questionnaire was collected only once, either post-educational unit (school 2) or post-basic information (school 4).

All tests of significance were based on $p<0.05$ level and confidence interval of $95 \%$ was applied.

In order to evaluate the feasibility of the educational unit, frequencies of students rating of the educational unit were used. Furthermore, a research assistant coded the transcripts of the semi-structured interviews and interrater reliability was tested with another research assistant coding the transcript. Mean-level results and distributions are presented at a descriptive level.

\section{Results}

\section{Sample Characteristics}

For the pilot study, four schools were contacted. All four contacted schools agreed to participate. One junior high school, one junior-senior high school and two academic high schools (see Appendix 2 (a)) constituted the pilot sample. One school was located in the city centre (school 1) and schools 2, 3, and 4 were located in a district of Berlin adjacent to the city centre. All schools were contacted initially by email or postal letter and preparatory telephone calls were made. At one school, an additional appointment was made in advance because more detailed information, regarding on-site procedures, was requested. The four enrolled schools had 41 school classes in total, grades 9 to 11, and 863 participating students, with an average age of 14.8 years, $49.4 \%$ of whom were female (see Table 1 ). 
Table 1

General characteristics of schools and students included in the pilot study

\begin{tabular}{|c|c|c|c|c|c|}
\hline & Total & $\begin{array}{l}\text { School } \\
1 \\
\text { ECC }\end{array}$ & $\begin{array}{l}\text { School } 2 \\
\text { ECC }\end{array}$ & $\begin{array}{l}\text { School } 3 \\
\text { ECC }\end{array}$ & $\begin{array}{l}\text { School } 4 \\
\text { LIIC }\end{array}$ \\
\hline $\begin{array}{l}\text { No. of days } \\
\text { present at school }\end{array}$ & 18 & 5 & 5 & 3 & 5 \\
\hline School type & $\begin{array}{l}\text { Public } \\
\text { schools }\end{array}$ & $\begin{array}{l}\text { Junior } \\
\text { high } \\
\text { school }\end{array}$ & $\begin{array}{l}\text { Junior-senior } \\
\text { high school }\end{array}$ & $\begin{array}{l}\text { Academic } \\
\text { high school }\end{array}$ & $\begin{array}{l}\text { Academic } \\
\text { high school }\end{array}$ \\
\hline No. of classes & 41 & 8 & 13 & 6 & 14 \\
\hline No. of students & 863 & 161 & 292 & 130 & 280 \\
\hline$\varnothing$ no. students/class & 21.0 & 20.0 & 22.5 & 21.2 & 20.0 \\
\hline $\begin{array}{l}\emptyset \text { age in years } \\
\text { ( } S D \text { in years) }\end{array}$ & $\begin{array}{l}14.8 \\
(1.0)\end{array}$ & $\begin{array}{l}14.8 \\
(0.8)\end{array}$ & $\begin{array}{l}14.9 \\
(1.0)\end{array}$ & $\begin{array}{l}14.6 \\
(1.0)\end{array}$ & $\begin{array}{l}14.9 \\
(1.0)\end{array}$ \\
\hline Female, \% & 49.4 & 41.5 & 48.5 & 50.4 & 54.3 \\
\hline $\begin{array}{l}\varnothing \text { Household size } \\
\text { - people (SD) }\end{array}$ & $\begin{array}{l}4.2 \\
(1.5)\end{array}$ & $\begin{array}{l}4.7 \\
(1.7)\end{array}$ & $\begin{array}{l}4.3 \\
(1.5)\end{array}$ & $\begin{array}{l}4.2 \\
(1.5)\end{array}$ & $\begin{array}{l}3.8 \\
(1.2)\end{array}$ \\
\hline Room, yes in \% & 74.8 & 52.8 & 75.3 & 74.4 & 87.2 \\
\hline Low SES, \% & 35.3 & 65.8 & 40.7 & 27.3 & 15.2 \\
\hline $\begin{array}{l}\text { Foreign language } \\
\text { background, } \%\end{array}$ & 47.2 & 87.9 & 48.0 & 45.2 & 23.8 \\
\hline
\end{tabular}

\section{Vaccination Status}

Out of the total sample, 437 students (50.6\%) brought their vaccination card to school (see Table 2). The check of the vaccination cards yielded the possibility to identify the vaccination status, this includes how many doses someone had received from a vaccine and whether there was an indication/need for vaccination according to the official vaccination recommendations (STIKO).

According to the check of vaccination cards, 16 students (3.7\%) showed a need for MMR vaccination. In the past, these students had received either only one vaccination or no vaccination against mumps, measles and/or rubella at all. Of these 16 students with a need for vaccination, in this study 11 (68.8\%) were vaccinated on-site.

For Tdap-IPV vaccination, following the check of vaccination cards, 36 students (8.2\%) in the past had only received four doses of a tetanus, diphtheria, or pertussis vaccination (basic immunization until age 
of 14 months) and a definite need for a booster vaccination. Another 152 students (34.8\%) had received five doses of tetanus, diphtheria, and/or pertussis. Students with five doses showed a conditional need for a booster vaccination, a sixth shot is recommended if the time distance to the last vaccination is at least greater than five years. Regarding polio, only 148 students (33.9\%) had received up to four doses of polio vaccination and had a need for a single booster with Tdap-IPV. In this study 68 students were vaccinated with Tdap-IPV. It is not possible to provide information on the relative ratio of vaccinated students to the need of Tdap-IPV vaccination regarding tetanus, diphtheria, and pertussis. For those infectious diseases between vaccination doses five and six, five years should pass, and for the students with five vaccinations the time span to the last vaccination was not documented in pilot study. 
Table 2

Vaccination status for students with vaccination card present and number of doses delivered on-site

\begin{tabular}{|c|c|c|}
\hline $\begin{array}{l}\text { Vaccination status } \\
\text { for students with } \\
\text { vaccination card } \\
\text { present }\end{array}$ & Before intervention & $\begin{array}{l}\text { Vaccine } \\
\text { doses } \\
\text { delivered on- } \\
\text { site }\end{array}$ \\
\hline \multicolumn{3}{|l|}{$N=437$} \\
\hline $\begin{array}{l}\text { ( } 50.6 \% \text { of the total } \\
\text { sample) }\end{array}$ & & \\
\hline
\end{tabular}

\begin{tabular}{|c|c|c|c|c|c|c|c|c|}
\hline & \multicolumn{2}{|c|}{0 doses $^{b}$} & 1 dose $^{b}$ & \multicolumn{2}{|c|}{2 doses $^{d}$} & $>2$ dos & & \multirow[t]{2}{*}{ MMR, $\mathrm{n}$} \\
\hline & \multicolumn{7}{|c|}{$\begin{array}{l}\text { Basic immunization until age } 2 \text { years } \\
(23 \text { months), } \\
2 \text { doses }^{\text {a }}\end{array}$} & \\
\hline Mumps, n (\%) & \multicolumn{2}{|l|}{$3(0.7)$} & $13(3.0)$ & \multicolumn{2}{|c|}{419 (95.9) } & $2(0.4)$ & & \multirow[t]{3}{*}{11} \\
\hline Measles, n (\%) & \multicolumn{2}{|l|}{$2(0.4)$} & $12(2.8)$ & \multicolumn{2}{|c|}{418 (95.7) } & \multicolumn{2}{|l|}{$5(1.1)$} & \\
\hline \multirow[t]{3}{*}{ Rubella, n (\%) } & \multicolumn{2}{|l|}{$3(0.7)$} & $13(3.0)$ & \multicolumn{2}{|c|}{418 (95.7) } & \multicolumn{2}{|l|}{$3(0.7)$} & \\
\hline & $\begin{array}{l}0-1 \\
\text { doses } \\
b\end{array}$ & $\begin{array}{l}2-3 \\
\text { doses } \\
b\end{array}$ & $4 \mathrm{do}$ & & 5 dose & & $\begin{array}{l}6 \\
\text { doses } \\
\text { d }\end{array}$ & Tdap-IPV, n \\
\hline & \multicolumn{4}{|c|}{$\begin{array}{l}\text { Basic immunization until age } \\
1.3 \text { years ( } 14 \text { months), } \\
4 \text { doses }^{\text {a }}\end{array}$} & \multicolumn{3}{|c|}{$\begin{array}{l}\text { Booster immunization, } \\
\text { every } 5-10 \text { years }^{a}\end{array}$} & \\
\hline Tetanus, n (\%) & $\begin{array}{l}10 \\
(2.3)\end{array}$ & $7(1.6)$ & 19 & & $150(3$ & & $\begin{array}{l}251 \\
(57.4)\end{array}$ & 63 \\
\hline Diphtheria, n (\%) & $\begin{array}{l}10 \\
(2.3)\end{array}$ & $7(1.6)$ & 19( & & 151 (3 & & $\begin{array}{l}250 \\
(57.2)\end{array}$ & \\
\hline \multirow[t]{2}{*}{ Pertussis, n (\%) } & $\begin{array}{l}13 \\
(3.0)\end{array}$ & $7(1.6)$ & 18 & & 152 (3 & & $\begin{array}{l}247 \\
(56.5)\end{array}$ & \\
\hline & \multicolumn{4}{|c|}{$\begin{array}{l}\text { Basic immunization until age } \\
1.3 \text { years ( } 14 \text { months), } \\
4 \text { doses }\end{array}$} & \multicolumn{3}{|c|}{$\begin{array}{l}1 \text { Booster } \\
\text { immunization, } \\
\text { at age } 9- \\
14 \text { years }^{\text {a }}\end{array}$} & \\
\hline \multicolumn{9}{|c|}{$\begin{array}{l}\text { a Vaccination recommendation of the German Vaccination Committee (Ständige Impfkommission am } \\
\text { Robert Koch-Institut, STIKO [29]); b indication for a vaccination; }{ }^{c} \text { conditional indication for a } \\
\text { vaccination for tetanus, diphtheria and/or pertussis, depending on time lag to previous vaccination; }{ }^{d} \\
\text { no indication for a vaccination }\end{array}$} \\
\hline
\end{tabular}




\begin{tabular}{|c|c|c|c|c|c|c|}
\hline $\begin{array}{l}\text { Vaccination status } \\
\text { for students with } \\
\text { vaccination card } \\
\text { present } \\
N=437 \\
(50.6 \% \text { of the total } \\
\text { sample) }\end{array}$ & Befor & tervent & & & & $\begin{array}{l}\text { Vaccine } \\
\text { doses } \\
\text { delivered on- } \\
\text { site }\end{array}$ \\
\hline Polio, n (\%) & $\begin{array}{l}14 \\
(3.2)\end{array}$ & $\begin{array}{l}13 \\
(3.0)\end{array}$ & $\begin{array}{l}121 \\
(27.7)\end{array}$ & 269 (61.6) & $\begin{array}{l}20 \\
(4.5)\end{array}$ & \\
\hline \multicolumn{7}{|c|}{$\begin{array}{l}\text { a Vaccination recommendation of the German Vaccination Committee (Ständige Impfkommission am } \\
\text { Robert Koch-Institut, STIKO [29]); b indication for a vaccination; }{ }^{c} \text { conditional indication for a } \\
\text { vaccination for tetanus, diphtheria and/or pertussis, depending on time lag to previous vaccination; }{ }^{d} \\
\text { no indication for a vaccination }\end{array}$} \\
\hline
\end{tabular}

The documentation for the vaccination documents (vaccination card, parental consent) was expanded in the course of the pilot study to take into account on-site feedback from physicians regarding parental consent/dissent (explicit objection) to vaccination. Originally, parental consent was only recorded for minors who received a vaccination. Furthermore each minor also had to agree to the vaccination. In addition, some parents explicitly objected to the on-site vaccination. At schools 3 and $4(n=297)$ in total 121 students (40.7\%) presented their vaccination card, $78(64.5 \%)$ of them also had a written parental consent. However, 9 (3.0\%) of these students had a written objection from their parents against the vaccination. Fifteen students (5.1\%) without a vaccination card nevertheless had a parental consent with them. A further 23 students (7.7\%) without a vaccination card present additionally had a written objection from their parents opposing vaccination.

\section{Knowledge Scale}

Concerning the vaccination-related knowledge items with repeated measures (ECC: pre- and posteducational unit, school 1 and 3), applying GEE models for each item, the percent of correct responses for the seven knowledge items before the educational unit took place ranged from $22 \%(\mathrm{Cl} 16 \% / 28 \%)$ to $70 \%$ (Cl 65\%/76\%) correct responses. After the educational unit took place, these rates increased to $32 \%(\mathrm{Cl}$ $23 \% / 40 \%)$ to $86 \%(\mathrm{Cl} 81 \% / 92 \%)$ correct responses (Table 3 ).

Item 5 (Bacteria, see Fig. 2) was excluded from all further analysis and thus not included in the formation of the knowledge sum scores. Additionally to reported difficulties in understanding of students in the field, it showed no sensitivity to change from pre- to post-educational unit (Table 3). 
Table 3

Amount of correct answers for the vaccination-related knowledge items with repeated measures

\begin{tabular}{|c|c|c|c|c|}
\hline \multirow{3}{*}{$\begin{array}{l}\text { Measure } \\
\text { Condition }\end{array}$} & \multicolumn{4}{|c|}{$\begin{array}{l}\text { Knowledge Items (school 1, 3) } \\
\text { Generalized Estimated Equations for each item } \\
\text { (imputed knowledge items, covariates: age, gender, SES) }\end{array}$} \\
\hline & \multicolumn{2}{|c|}{ pre-educational unit } & \multicolumn{2}{|c|}{ post-educational unit } \\
\hline & $\begin{array}{l}\% \text { correct } \\
\text { responses } \\
\text { (Cl) }\end{array}$ & $\begin{array}{l}\mathrm{N} \text { students, } \\
\text { classes, } \\
\text { schools }\end{array}$ & $\begin{array}{l}\% \text { correct } \\
\text { responses } \\
\text { (Cl) }\end{array}$ & $\begin{array}{l}\text { N students, } \\
\text { classes, } \\
\text { schools }\end{array}$ \\
\hline $\begin{array}{l}\text { ITEM1 } \\
\text { Childhood Disease }\end{array}$ & $22(16-28)$ & $287,14,2$ & $44(38-50)$ & $291,14,2$ \\
\hline $\begin{array}{l}\text { ITEM } 2 \\
\text { Herd Immunity }\end{array}$ & $39(32-46)$ & $287,14,2$ & $55(44-66)$ & $291,14,2$ \\
\hline $\begin{array}{l}\text { ITEM } 3 \\
\text { Immunization }\end{array}$ & $70(65-76)$ & $287,14,2$ & $80(76-84)$ & $291,14,2$ \\
\hline $\begin{array}{l}\text { ITEM } 4 \\
\text { Measles Outbreak }\end{array}$ & $61(54-69)$ & $287,14,2$ & $86(81-90)$ & $291,14,2$ \\
\hline $\begin{array}{l}\text { ITEM } 5 \\
\text { Bacteria a }\end{array}$ & $34(30-39)$ & $258,14,2$ & $32(23-40)$ & $283,14,2$ \\
\hline $\begin{array}{l}\text { ITEM } 6 \\
\text { Infertility }\end{array}$ & $35(24-46)$ & $127,6,1$ & $82(78-86)$ & $130,6,1$ \\
\hline $\begin{array}{l}\text { ITEM } 7 \\
\text { Pregnancy } \\
\text { Malformation }\end{array}$ & $37(27-46)$ & $127,6,1$ & $68(61-75)$ & $130,6,1$ \\
\hline
\end{tabular}

Based on the results displayed for every knowledge item, the final knowledge items were selected and 4and 6-item sum scores were computed. All scale analyses were performed with LMM. With LMM it is possible to account for between-class and between-school variation as well as class-level male/female ratio, age and SES.

Knowledge sum score, change from pre- to post-educational unit: Concerning the 4-item knowledge sum score, for school 1 and school 3 there were two data points for each student, as in those schools the students worked on the questionnaire both pre- and post-educational unit (i.e., 578 data points, 2 schools, 14 classes, 2 occasions, mean age 14.6 years, $48.0 \%$ female). The LMM showed a significant change $(B=-.69, \mathrm{Cl}-.86 /-.53, \mathrm{p}<.001)$ from pre- $(\mathrm{M}=1.92 . \mathrm{Cl} 1.76 / 2.08)$ to post- $(\mathrm{M}=2.61, \mathrm{Cl} 2.46 / 2.77)$ educational unit. 
The pre-post analysis with the 6 final knowledge items (i.e. 6-item knowledge sum score) included $127 / 130$ students from 1 school ( 6 classes, mean age 14.6 years, $50 \%$ female). The LMM implied a significant change $(B=-1.55, C l-1.83 /-1.27, p<.001)$ from pre- $(M=2.84, C l 2.69 / 3.10)$ to post- $(M=4.45$, $\mathrm{Cl}$ 4.26/4.64) educational unit.

The distribution of the number of correct answers (4-item/6-item sum score) for the students included in the pre-post condition is shown in Fig. 3.

Knowledge sum score post-basic information versus post-educational unit: Furthermore, the distribution of the correct answers was compared for the 4-item sum score between two schools, where the questionnaire was applied only once. In school 2 the questionnaire was applied post-educational unit (292 students, 13 classes, mean age 14.9 years, $48.5 \%$ female) and in school 4 post-basic information unit (280 students, 14 classes, mean age 14.9 years. 54.3\% female). The LMM showed a significant difference $(\mathrm{B}=-0.64, \mathrm{Cl}-0.94 /-0.33, \mathrm{p}<.001)$ indicating a higher knowledge sum score for students posteducational unit $(\mathrm{M}=2.98, \mathrm{Cl} 2.78 / 3.17)$ compared to students post-basic information $(\mathrm{M}=2.34, \mathrm{Cl}$ 2.15/2.54).

\section{Self-efficacy Scale}

For perceived self-efficacy, the item means ranged between $\mathrm{M}=2.5(\mathrm{Cl} 2.4 / 2.6)$ and $\mathrm{M}=3.4(\mathrm{Cl} 3.3 / 3.5)$ post-basic information and between $\mathrm{M}=2.9(\mathrm{Cl} 2.8 / 3.0)$ and $\mathrm{M}=3.5(\mathrm{Cl} 3.5 / 3.6)$ post-educational unit (Table 4). 
Table 4

Means (range: 1-4) of the perceived self-efficacy items with repeated measures

\begin{tabular}{|c|c|c|c|c|}
\hline Measure & \multicolumn{4}{|c|}{$\begin{array}{l}\text { Linear Mixed Models - for each item } \\
\text { (imputed perceived self-efficacy items, covariates: age, gender, } \\
\text { SES) }\end{array}$} \\
\hline \multirow[t]{2}{*}{ Condition } & \multicolumn{2}{|c|}{ pre-educational unit } & \multicolumn{2}{|c|}{ post educational unit } \\
\hline & $\begin{array}{l}\text { Mean } \\
\text { (Cl) }\end{array}$ & $\begin{array}{l}\mathrm{N} \text { students, } \\
\text { classes, schools }\end{array}$ & $\begin{array}{l}\text { Mean } \\
(\mathrm{Cl})\end{array}$ & $\begin{array}{l}\mathrm{N} \text { students, } \\
\text { classes, schools }\end{array}$ \\
\hline $\begin{array}{l}\text { ITEM1 } \\
\text { Why do I need vaccinations }\end{array}$ & $\begin{array}{l}3.4 \\
(3.3-3.5)\end{array}$ & $287,14,2$ & $\begin{array}{l}3.5 \\
(3.5-3.6)\end{array}$ & $291,14,2$ \\
\hline $\begin{array}{l}\text { ITEM } 2 \\
\text { Which vaccinations do I need }\end{array}$ & $\begin{array}{l}2.7 \\
(2.6-2.8)\end{array}$ & $287,14,2$ & $\begin{array}{l}3.2 \\
(3.1-3.3)\end{array}$ & $291,14,2$ \\
\hline $\begin{array}{l}\text { ITEM } 3 \\
\text { Trustfulness of information } \\
\text { (media) }\end{array}$ & $\begin{array}{l}2.5 \\
(2.4-2.6)\end{array}$ & $287,14,2$ & $\begin{array}{l}2.9 \\
(2.8-3.0)\end{array}$ & $291,14,2$ \\
\hline $\begin{array}{l}\text { ITEM } 4 \\
\text { Advice from friends and family }\end{array}$ & $\begin{array}{l}3.0 \\
(2.9-3.2)\end{array}$ & $287,14,2$ & $\begin{array}{l}3.1 \\
(3.0-3.3)\end{array}$ & $291,14,2$ \\
\hline $\begin{array}{l}\text { ITEM } 5 \\
\text { Advice from media }\end{array}$ & $\begin{array}{l}2.7 \\
(2.6-2.9)\end{array}$ & $287,14,2$ & $\begin{array}{l}3.0 \\
(2.9-3.2)\end{array}$ & $291,14,2$ \\
\hline
\end{tabular}

Internal consistency of the self-efficacy scale was alpha $=.67$ pre-educational unit assessments and alpha $=.76$ post-educational unit, indicating an adequate reliability of the self-efficacy scale. Exploring the factorial structure of the self-efficacy scale by means of EFA, a unidimensional factor solution was suggested by the scree plots before and after the class.

Using all available data from students that worked on the questionnaire pre- and post-educational unit (578 data points, 2 schools, 14 classes, 2 occasions; mean age 14.6 years, $48.0 \%$ female), an LMM, which accounted for between class variation, was applied. The model showed significant change pre to post of 0.3 points $(B=-0.20, \mathrm{Cl}-0.40 /-0.20, \mathrm{p}<.001)$ from $2.9(\mathrm{Cl} 2.78 / 3.00)$ to $3.2(\mathrm{Cl} 3.10 / 3.24)$ on the perceived self-efficacy scale (range from 1 to 4 ).

Furthermore, data from the other two schools were compared, where students worked on the questionnaire only once, either post-educational unit (school 2, 292 students, 13 classes, mean age 14.9 years, $48.5 \%$ female) or post-basic information ( 280 students, 14 classes, mean age 14.9 years. $54.3 \%$ female). Analysis revealed comparable results, showing a significant difference $(B=-0.26, \mathrm{Cl}-0.33 /-0.07, p$ $<.01)$ for items assessed post-basic information $(\mathrm{M}=2.96, \mathrm{Cl} 2.88 / 3.04)$ and post-educational unit $(\mathrm{M}=$ $3.15, \mathrm{Cl} 3.07 / 3.24)$.

\section{Educational Unit}


Content analysis of the five semi-structured interviews ( $n=12,58.3 \%$ female) showed that the length of the class was felt by all students to be appropriate. The teaching methods of the physicians were perceived as very good, especially the activating elements and the possibility of interactive exchange between the students and physicians. The social media post was rated as good or very good by four out of five groups. The content was considered modern, realistic, and easy to understand. Contents of the educational unit on the individual diseases were perceived as particularly interesting as well as social aspects (e.g. herd immunity) and the use of video materials. In addition, the students stated that their attitude to vaccination had not changed. However, the ECC was perceived as a positive learning opportunity. Additional information on the diseases described during the ECC (e.g. on effects of rubella during pregnancy) and on HPV was requested by three groups.

\section{Discussion}

The aim of the present pilot study was to test the feasibility of recruitment processes and on-site procedures of a planned school-based educational, on-site vaccination intervention among adolescents. A further purpose of this study was the evaluation of psychometric properties of instruments. The results of the current pilot study showed that the school-based on-site vaccination approach is feasible to improve vaccination rates. Students in all participating schools showed a good vaccination uptake rate after the pilot intervention. The recruitment strategies have proven successful in gaining access to schools that were comparable to those planned to be eligible for our main trial. Regarding the instruments' psychometric properties, our measurement tool for vaccination-related knowledge showed a reasonable sensitivity to change. In addition, the self-efficacy scale presented with a one-factor structure, was internally consistent, and self-efficacy levels regarding vaccination increased from before to after the educational unit.

For the successful implementation of the planned cluster randomized controlled trial, the pilot study showed that our recruitment procedures for schools to participate in an educational, on-site vaccination project are very promising. In comparison to other on-site vaccination interventions, we successfully included $100 \%$ of the contacted schools, which represents an above-average participation rate $[10,13$, 25-27]. To achieve an effective objective assessment of vaccination rates, it is also indispensable to gain a high participation rate of students providing vaccination documents (i.e. vaccination cards and signed consent forms). Half of the students enrolled in this pilot study presented their vaccination cards. The parental consent rate for minors, documented at school 3 and 4 , was about $65 \%$. The present participation rates thus corresponded to other on-site vaccination studies $[11,13,18,26,27]$. Regarding vaccinations carried out, 11 out of 16 students, about $69 \%$, with a need for vaccination received MMR vaccination. A total of 63 Tdap-IPV vaccine doses were administered. To be able to make a statement about the total amount of students who needed a booster vaccination, it must be possible to determine the time since the last Tdap IPV vaccination received. Due to insufficient information about the time passed since the last Tdap-IPV dose received, which should be at least 5 years between dose five and six [29], the relative rate for this vaccination cannot be determined. In sum, it is encouraging that the individual vaccination protection of MMR vaccination in this study increased strongly. The need for the 
Tdap-IPV vaccination seems to be relatively high, since about $15 \%$ of all students with a vaccination card had been vaccinated, nevertheless documentation should be expanded. Over all the applied recruitment processes and the on-site vaccination procedure seem to be a feasible procedure for the planned main trial.

As a result of the pilot study, we took the initiative to improve documentation procedures for our staff onsite. For the Tdap-IPV vaccination, for example, in addition to the number of doses received also the time interval to the last Tdap-IPV vaccination are to be recorded in the main trial from the beginning on, as after completing basic immunization (4 doses) a booster vaccination is recommended every five to ten years [29]. Without this information, no statement can be made about the need for vaccination. Further, by additionally documenting written parental objection to vaccination, insightful information was provided and should be included in the subsequent study. Parents were informed in advance that a nonsignature of the consent form is sufficient if they did not want a vaccination to be carried out. This information can be used as an indicator whether there is an increased need for further interaction with parents or for which subgroups this way becomes apparent. In the pilot study, the documentation of parental objection was already carried out for two schools, the number was relatively low with nine objections (3.0\%). Wether there is a need for further interaction cannot be adequately evaluated, because the informational value is quite limited due to the number and characteristics of the two schools. Both were academic high schools with above-average SES. In combination with these indicators, laggards should also be recorded. The number of laggards provides data on who will not be vaccinated immediately after class, but later in the week. In this way, it is possible to determine whether a visit of several days to a school makes sense, for which school type and to what extent students from intervention groups take the educational components as a cue to action to still take advantage of the onsite vaccination offer. A broader documentation of data on vaccination need, parental consent process and use of vaccination should be used in the future to increase the significance of a study.

Testing the previously developed theory- and evidence-based educational unit yielded helpful insights regarding which topics seem to be of a higher relevance to the students. According to the results of the qualitative interviews, following the pilot study we have slightly adapted timing of contents of the educational unit. This resulted in a stronger focus on infectious diseases and social aspects. Length, thematic focus as well as interactive content and the implementation by a physician were considered positive by the majority of the students and could thus be adopted for the planned study.

The improvement in vaccination-related knowledge $[12,13,15,25]$ as well as the increase in perceived self-efficacy $[12,14,18]$ are in line with previous findings. There was an adjustment of knowledge items used (see Fig. 2), because in week 1 (school 1) the physicians on-site reported frequent comprehension problems of some students with one of the items. Two further items were introduced. Both newly added items addressed complications of infectious diseases.

The findings of the pilot appear to indicate that it seems possible to increase the vaccination rate for mumps, measles, and rubella as well as tetanus, diphtheria, pertussis, and polio together with 
vaccination-related knowledge as well as self-efficacy.

Strengths and limitations

Key strengths of our pilot study include the large sample size and the elaborated design of the study. The design allowed us to test the feasibility and properties under comparable conditions as in the planned main trial; however, the design provided the opportunity for adjustments and for comparisons of different assessment strategies (e.g. pre-post, post only with and without educational unit) as well.

There are several limitations to this study. First, due to the small number of schools, we were not able to compare feasibility and psychometric properties of assessment tools differentially for school type. Nonetheless, in the cluster randomized main trial, we will be able to account for these variations. Due to administrative reasons, migration status on individual level [35] and a scale assessing SES, including information on the parents [36], could not be evaluated. This will be possible in the main trial. More detailed information, also on an individual level, is promising, as studies have shown that vaccination interventions as well as education interventions vary in their effectiveness as a function of migration status [37, 38]. Finally, although we accounted for confounders statistically, we did not allocate the schools randomly, thus, full control over confounders was not given and results may be biased. However, the purpose of this pilot study was to get first insights in the feasibility and psychometrics, for which the current study design was appropriate.

Implications for research, policy and practice

This pilot study has direct implications for the planned main study, particularly with respect to the reliability of the secondary outcome measures, but also concerning recruitment and data handling structures. Further, we could show substantial vaccination rates as well as rates of change regarding increase of knowledge and self-efficacy attributed to the educational unit. Moreover, future research may use the assessments in other vaccination-related studies, either interventional or observational. We provided findings for MMR and Tdap-IPV vaccinations; however, future research should include other types of vaccination in the school-based approach such as STI/HPV vaccinations as well [12-19]. Further, we developed our intervention and procedures in a capital city of a high-income country. Future studies should test comparable approaches in low and middle-income countries and in more rural areas, as effects may even be larger in these regions.

It proved to be feasible and effective to provide an on-site school-based vaccination program in combination with a health education intervention. The intervention may increase health literacy levels of adolescents and lower the structural barriers for vaccination at the same time. Further, this intervention strategy may be a cost effective and scalable way and thus constitutes an additional public health strategy that might complement existing endeavours to improve vaccination rates.

\section{Conclusion}


We found a school-based educational and on-site vaccination intervention to be feasible and the vaccination-related instruments to show adequate psychometric properties. Further pursuing this line of research could have the potential to improve the currently non-optimal vaccination rates and thus help to protect adolescents and people of different ages from infectious diseases.

\section{List Of Abbreviations}

LMM = Linear Mixed Model

$\mathrm{MI}=$ Multiple Imputation

MMR = measles, mumps, rubella

Tdap-IPV = tetanus, diphteria, pertussis, polio

$\mathrm{OECD}=$ Organisation for Economic Co-operation and Development

SES $=$ socioeconomic status

\section{Declarations}

Ethics approval and consent to participate: The Ethics Committee of the Charité - Universitätsmedizin Berlin, approved the procedure of the main trial, which was also used in the pilot study (EA1/059/17). All students, including those underage, were asked for their consent right before vaccination took place. Parental consent was obtained in advance, in case students were underage.

Consent for publication: Not applicable.

Availability of data and material: The datasets generated and analyzed during the current study are not publicly available for participants' confidentiality but are available from the corresponding author on reasonable request

Competing interests: None declared.

Funding: The study was funded by the German Federal Ministry of Health (BMG; Grant number 1503/53105).

Authors' contributions: The study organisation and management was carried out by the study team (i.e., NB, JS). The analyses were conducted by PG and NB. The educational unit was developed by NB with advice from PG and JS. NW was involved in the data collection and as well as in the development of the literature background of school-based vaccination interventions. NK provided content input in the area of behavior change theory, which formed the basis for the conception of the teaching unit, as well as valuable feedback on the data analysis of the pilot study. All authors read and approved the final manuscript. 
Acknowledgements: The authors would like to thank the entire Prevention Bus team of Charité Universitätsmedizin Berlin, including physicians, nurses and our bus driver for their positive influence on the project during the planning and first implementation phase. We would also like to thank our team in the office for their support in planning and recruiting, as well as the Chief Medical Officer of Charité, Prof. Dr. Ulrich Frei for his continuous support of the research team. Furthermore, we would like to thank all headmasters, teachers, secretaries, parents and students who participated in the pilot study and gave valuable feedback on our procedures on-site as well as on the educational unit. We would also like to thank Lutz Fournell who, with his confident commitment, made the start of the pilot so efficacious. Additionally, we would like to thank Gudrun Widders, medical officer, head of the health department of Spandau (a district of Berlin) for her valuable support in the pilot study. Further, we acknowledge support from the German Research Foundation (DFG) and the Open Access Publication Fund of Charité Universitätsmedizin Berlin.

\section{References}

1. World Health Organization: Global Vaccine Action Plan 2011-2020. In. Geneva, Switzerland; 2012.

2. World Health Organization: Assessment report of the Global Vaccine Action Plan. Strategic Advisory Group of Experts on Immunization. In. Edited by World Health Organization. Geneva, Switzerland; 2018.

3. Pan American Health Organization, World Health Organization: Epidemiological Update: Measles. In. D.C.: PAHO/WHO; 2019.

4. Robert Koch-Institut: [Vaccination rates at the initial school examination in Germany 2017] Impfquoten bei der Schuleingangsuntersuchung in Deutschland 2017 Epid Bull 2019, 2019; 18:147 153.

5. Robert Koch-Institut: [Vaccination rates at the initial school examination in Germany 2015] Impfquoten bei der Schuleingangsuntersuchung in Deutschland 2015 Epid Bull 2017, 2017; 16:137 142

6. Robert Koch-Institut: [Vaccination rates at the initial school examination in Germany 2014] Impfquoten bei der Schuleingangsuntersuchung in Deutschland 2014. Epid Bull 2016(2016; 16):129 142.

7. Wolfe S, Centers for Disease Control Prevention: Epidemiology and prevention of vaccine-preventable diseases. Atlanta: US Department of Health \& Human Services, Centers for Disease Control and Prevention; 2015.

8. Takahashi K, Ohkusa Y, Kim J-Y: The economic disease burden of measles in Japan and a benefit cost analysis of vaccination, a retrospective study. BMC health services research 2011, 11(1):254.

9. Bester JC: Measles and measles vaccination: a review. JAMA pediatrics 2016, 170(12):1209-1215.

10. Humiston SG, Schaffer SJ, Szilagyi PG, Long CE, Chappel TR, Blumkin AK, Szydlowski J, Kolasa MS: Seasonal influenza vaccination at school: a randomized controlled trial. Am J Prev Med 2014, 46(1):1-9. 
11. Daley MF, Kempe A, Pyrzanowski J, Vogt TM, Dickinson LM, Kile D, Fang H, Rinehart DJ, Shlay JC: School-located vaccination of adolescents with insurance billing: cost, reimbursement, and vaccination outcomes. J Adolesc Health 2014, 54(3):282-288.

12. Gottvall M, Tyden T, Hoglund AT, Larsson M: Knowledge of human papillomavirus among high school students can be increased by an educational intervention. Int J STD AIDS 2010, 21(8):558562.

13. Grandahl M, Rosenblad A, Stenhammar C, Tyden T, Westerling R, Larsson M, Oscarsson M, Andrae B, Dalianis T, Neveus T: School-based intervention for the prevention of HPV among adolescents: a cluster randomised controlled study. BMJ Open 2016, 6(1):e009875.

14. Coyle KK, Glassman JR, Franks HM, Campe SM, Denner J, Lepore GM: Interventions to reduce sexual risk behaviors among youth in alternative schools: a randomized controlled trial. $J$ Adolesc Health 2013, 53(1):68-78.

15. Kwan TT, Tam KF, Lee PW, Chan KK, Ngan HY: The effect of school-based cervical cancer education on perceptions towards human papillomavirus vaccination among Hong Kong Chinese adolescent girls. Patient Educ Couns 2011, 84(1):118-122.

16. Hill CA, Abraham C: School-based, randomised controlled trial of an evidence-based condom promotion leaflet. Psychol Health 2008, 23(1):41-56.

17. Cox DS, Cox AD, Sturm L, Zimet G: Behavioral interventions to increase HPV vaccination acceptability among mothers of young girls. Health Psychology 2010, 29(1):29.

18. Rickert VI, Auslander BA, Cox DS, Rosenthal SL, Rupp RE, Zimet GD: School-based HPV immunization of young adolescents: effects of two brief health interventions. Hum Vaccin Immunother 2015, 11(2):315-321.

19. Wegwarth O, Kurzenhauser-Carstens S, Gigerenzer G: Overcoming the knowledge-behavior gap: The effect of evidence-based HPV vaccination leaflets on understanding, intention, and actual vaccination decision. Vaccine 2014, 32(12):1388-1393.

20. Rogers RW: A protection motivation theory of fear appeals and attitude change. The journal of psychology 1975, 91(1):93-114.

21. Bandura A: Social cognitive theory: An agentic perspective. Annual review of psychology 2001, 52(1):1-26.

22. Bandura A: Social foundations of thought and action. Englewood Cliffs, NJ 1986.

23. Becker MH: The health belief model and personal health behavior. Health education monographs 1974, 2:324-473.

24. Rosenstock IM: Historical origins of the health belief model. Health education monographs 1974, 2(4):328-335.

25. Davies C, Skinner SR, Stoney T, Marshall HS, Collins J, Jones J, Hutton H, Parrella A, Cooper S, McGeechan $\mathrm{K}$ et al: 'Is it like one of those infectious kind of things?' The importance of educating young people about HPV and HPV vaccination at school. Sex Education 2017, 17(3):256-275. 
26. Forster AS, Cornelius V, Rockliffe L, Marlow LA, Bedford H, Waller J: A cluster randomised feasibility study of an adolescent incentive intervention to increase uptake of HPV vaccination. Br J Cancer 2017.

27. Skinner SR, Imberger A, Nolan T, Glover S, Bowes G: Randomised controlled trial of an educational strategy to increase school-based adolescent hepatitis B vaccination. Australian and New Zealand Journal of Public Health 2000, 24(3):298-304.

28. Gellert P, Bethke N, Seybold J: School-based educational and on-site vaccination intervention among adolescents: study protocol of a cluster randomised controlled trial. BMJ open 2019, 9(1):e025113.

29. Ständige Impfkommission am Robert Koch-Institut (STIKO): [Vaccination recommendations of the German Vaccination Committee (STIKO) at the Robert-Koch Institut - 2016/2017] Empfehlungen der Ständigen Impfkommission (STIKO) am Robert Koch-Institut - 2016/2017. Epid Bull 2016, 34/2016.

30. Deutsches Grünes Kreuz e.V.: [informed consent] Aufklärung - Nr. 7: MMR Englisch/English, Information, Combination vaccination against measles, mumps and rubella. In:

Informationsmaterialien zum Impfen [Information material on vaccination]. Edited by Institut R-K. https://www.rki.de/DE/Content/Infekt/Impfen/Materialien/Downloads-Tdap-IPV/Tdap-IPVenglisch.pdf;jsessionid=439C7AB283EC432C997159384FDF666A.2_cid390?_blob=publicationFile; 2014.

31. Deutsches Grünes Kreuz e.V.: [informed consent] Aufklärung - Nr. 28: Tdap-IPV Englisch/English, about vaccinations against tetanus (lockjaw), diphtheria, pertussis (whooping cough), and polio (poliomyelitis). In: [Information material on vaccination] Informationsmaterialien zum Impfen Edited by Institut R-K. https://www.rki.de/DE/Content/Infekt/Impfen/Materialien/Downloads-TdapIPV/Tdap-IPV-englisch.pdf;jsessionid=439C7AB283EC432C997159384FDF666A.2_cid390? _blob=publicationFile; 2014.

32. Sørensen K, Van den Broucke S, Pelikan JM, Fullam J, Doyle G, Slonska Z, Kondilis B, Stoffels V, Osborne $\mathrm{RH}, \mathrm{Brand} \mathrm{H}$ : Measuring health literacy in populations: illuminating the design and development process of the European Health Literacy Survey Questionnaire (HLS-EU-Q). BMC public health 2013, 13(1):948.

33. Currie $C$, Molcho M, Boyce W, Holstein B, Torsheim T, Richter M: Researching health inequalities in adolescents: the development of the Health Behaviour in School-Aged Children (HBSC) family affluence scale. Social science \& medicine 2008, 66(6):1429-1436.

34. Boyce $W$, Torsheim $T$, Currie $C$, Zambon $A$ : The family affluence scale as a measure of national wealth: validation of an adolescent self-report measure. Social indicators research 2006, 78(3):473487.

35. Schenk L, Bau A-M, Borde T, Butler J, Lampert T, Neuhauser H, Razum O, Weilandt C: [Minimum set of indicators to measure migration status] Mindestindikatorensatz zur Erfassung des Migrationsstatus. Bundesgesundheitsblatt-Gesundheitsforschung-Gesundheitsschutz 2006, 49(9):853-860.

36. Delekat D, Kis A: [Health Monitoring Berlin - Special Report 2001 - 1 - The health situation of children in Berlin] Gesundheitsberichterstattung Berlin - Spezialbericht 2001 - 1 - Zur gesundheitlichen Lage 
von Kindern in Berlin. In. Berlin; 2001.

37. Walter D, Atzpodien K, Pins C, Wichmann O, Reiter S: [Factors influencing the uptake of vaccines by adolescents with migration background. A qualitative study of adolescents, mothers, and physicians] Einflussfaktoren auf die Inanspruchnahme von Impfungen durch Jugendliche mit Migrationshintergrund. Bundesgesundheitsblatt, Gesundheitsforschung, Gesundheitsschutz 2013, 56(10):1368-1375.

38. Centers for Disease Control and Prevention: National, state, and local area vaccination coverage among adolescents aged 13-17 years-United States. MMWR Morb Mortal Wkly Rep 2010, 2010;59:1018-1023.

\section{Figures}




\section{On-site procedure}

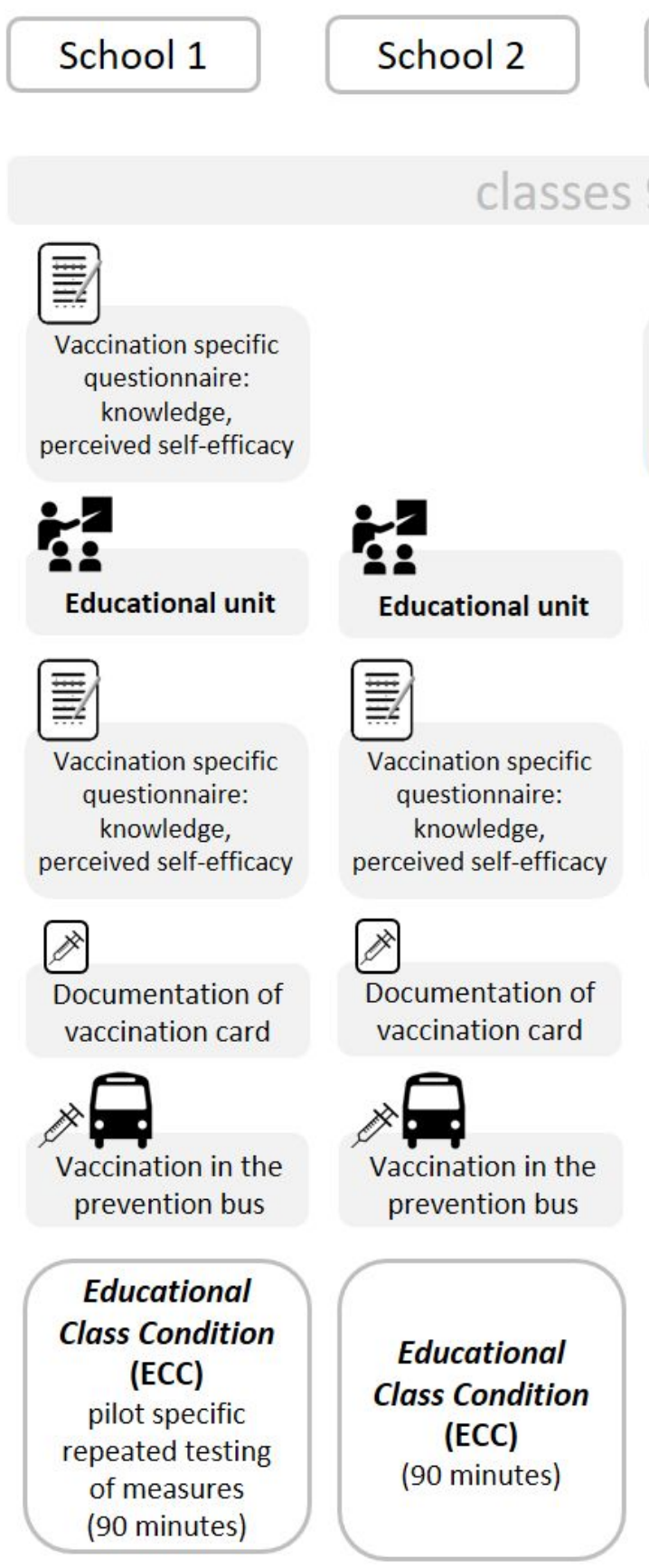

\section{School 3}

\section{School 4}

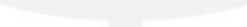

Vaccination specific questionnaire: knowledge, perceived self-efficacy

Educational unit

Vaccination specific questionnaire: knowledge, perceived self-efficacy

Documentation of

accination in the

\section{Educational} Class Condition (ECC) of measures (90 minutes)
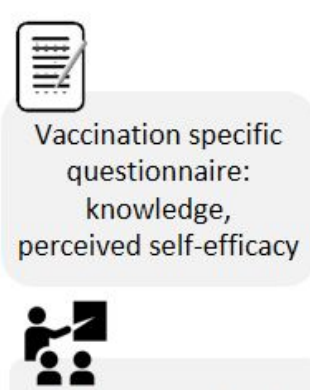

Educational unit

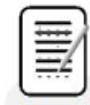

Vaccination specific questionnaire: knowledge, perceived self-efficacy<smiles>C1=CC12CC2</smiles>

Documentation of vaccination card

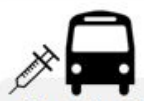

Vaccination in the prevention bus

Educational
Class Condition
(ECC)
pilot specific
repeated testing
of measures
(90 minutes)

层A

Basic information

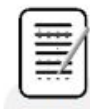

Vaccination specific questionnaire: knowledge, perceived self-efficacy<smiles>C1=CC12CC2</smiles>

Documentation of vaccination card

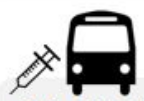

Vaccination in the prevention bus

Low Intensity

Information Condition

(LIIC)

(45 minutes)

\section{Figure 1}

On-site procedures for respective schools each carried out in the individual school class context. 


\section{School $1^{\text {a }}$}

Item 1-Childhood Disease Item 2-Herd Immunity

Item 3-Immunization

Item 4-Measles Outbreak

Item 5-Bacteria

Item 6-Infertility

Item 7-Pregnancy Malformation

\section{School 2}

School $3^{\text {a }}$

School 4

Figure 2

Vaccination-related knowledge items per school including newly introduced items at schools 3 and 4 . a two dots indicate repeated application of the items before and after the educational unit

\section{Knowledge Index}

\section{4-item sum score \\ School 1 and 3}

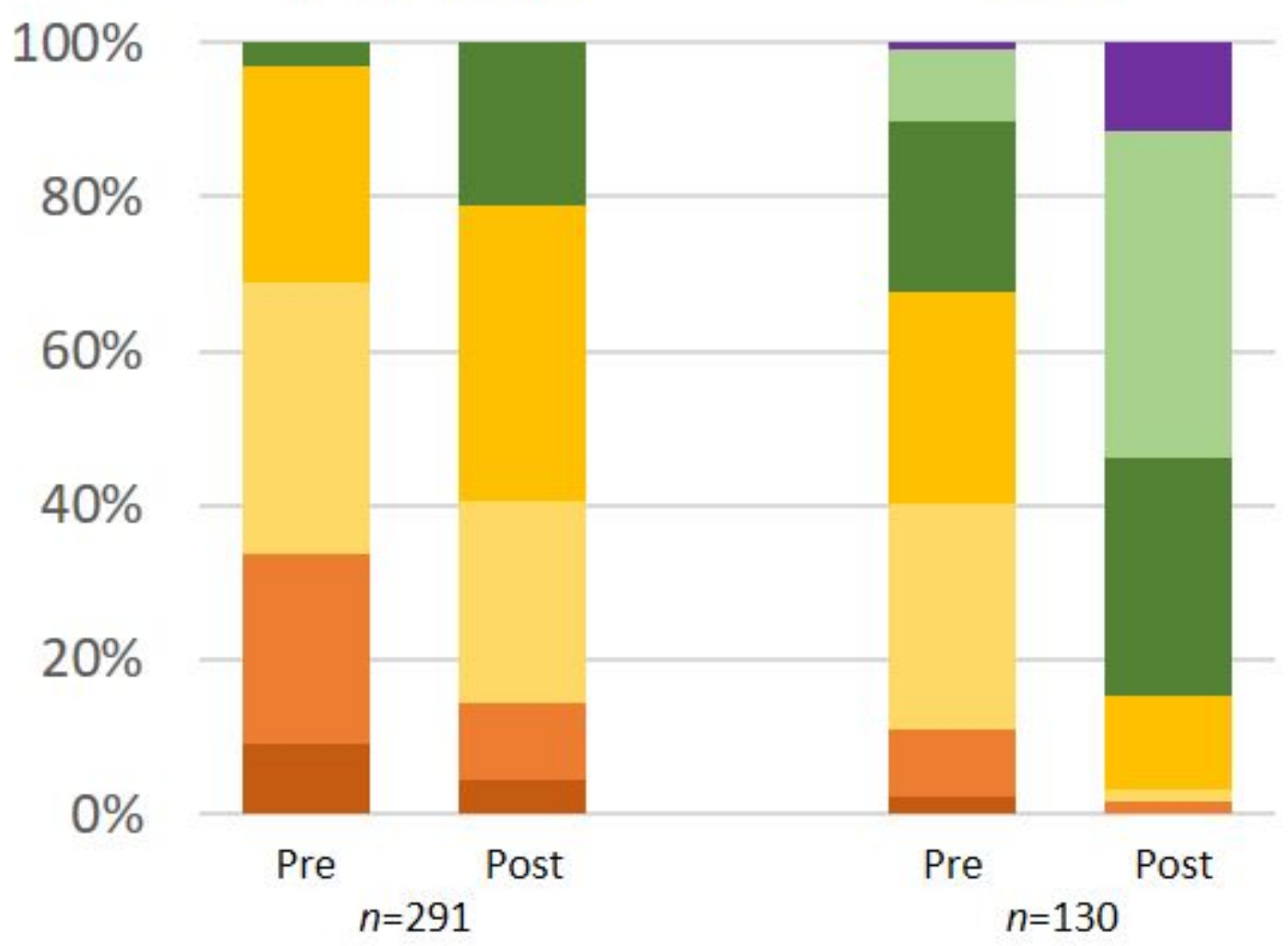

\section{6-item sum score}

School 3 
Distribution of the correct answers of the knowledge items for students with two data points

\section{Supplementary Files}

This is a list of supplementary files associated with this preprint. Click to download.

- PilotStudyfinalAppendixplaintext.docx 